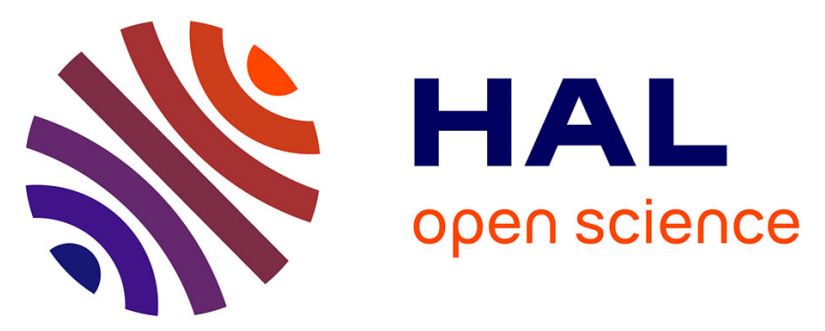

\title{
Development of a Local Health-Enhancing Physical Activity Policy Analysis Tool in France: CAPLA-Santé
}

Antoine Noël Racine, Aurélie van Hoye, Amandine Baron, Jean-Marie Garbarino, Bernard Massiera, Flore Lecomte, Marina Honta, Anne Vuillemin

\section{- To cite this version:}

Antoine Noël Racine, Aurélie van Hoye, Amandine Baron, Jean-Marie Garbarino, Bernard Massiera, et al.. Development of a Local Health-Enhancing Physical Activity Policy Analysis Tool in France: CAPLA-Santé. Health Promotion Practice, 2021, 22 (4), pp.540-548. 10.1177/1524839920916462 . hal-02865823

\section{HAL Id: hal-02865823 \\ https://hal.univ-cotedazur.fr/hal-02865823}

Submitted on 14 Jul 2020

HAL is a multi-disciplinary open access archive for the deposit and dissemination of scientific research documents, whether they are published or not. The documents may come from teaching and research institutions in France or abroad, or from public or private research centers.
L'archive ouverte pluridisciplinaire HAL, est destinée au dépôt et à la diffusion de documents scientifiques de niveau recherche, publiés ou non, émanant des établissements d'enseignement et de recherche français ou étrangers, des laboratoires publics ou privés. 


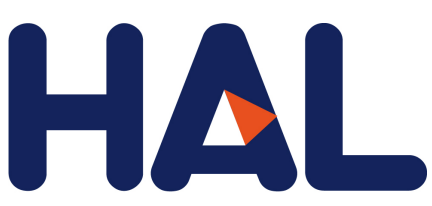

archives-ouvertes

\section{Development of a Local Health-Enhancing Physical Activity Policy Analysis Tool in France: CAPLA-Santé}

Antoine Noël Racine, Aurélie van Hoye, Amandine Baron, Flore Lecomte, Jean-Marie Garbarino, Bernard Massiera, Marina Honta, Anne Vuillemin

\section{- To cite this version:}

Antoine Noël Racine, Aurélie van Hoye, Amandine Baron, Flore Lecomte, Jean-Marie Garbarino, et al.. Development of a Local Health-Enhancing Physical Activity Policy Analysis Tool in France: CAPLA-Santé. Health Promotion Practice, SAGE Publications, 2020. hal-02865823

\section{HAL Id: hal-02865823 \\ https://hal.univ-cotedazur.fr/hal-02865823}

Submitted on 12 Jun 2020

HAL is a multi-disciplinary open access archive for the deposit and dissemination of scientific research documents, whether they are published or not. The documents may come from teaching and research institutions in France or abroad, or from public or private research centers.
L'archive ouverte pluridisciplinaire HAL, est destinée au dépôt et à la diffusion de documents scientifiques de niveau recherche, publiés ou non, émanant des établissements d'enseignement et de recherche français ou étrangers, des laboratoires publics ou privés. 


\title{
Development of a Local Health-Enhancing Physical Activity Policy Analysis Tool in France: CAPLA-Santé
}

\author{
Antoine Noël Racine, $\mathrm{MSc}^{1}{ }^{1}$ iD \\ Aurélie Van Hoye, $\mathrm{PhD}^{2}$ \\ Amandine Baron, $\mathrm{MSc}^{2,3}$ \\ Flore Lecomte, $\mathrm{MSc}^{3}$ \\ Jean-Marie Garbarino, $\mathrm{PhD}^{1}$ \\ Bernard Massiera, $\mathrm{PhD}^{1}$ \\ Marina Honta, $\mathrm{PhD}^{4}$ \\ Anne Vuillemin, $\mathrm{PhD}^{1}$ iD
}

The promotion of health-enhancing physical activity (HEPA) has become a key objective in public health policy. Therefore, based on the national HEPA Policy Audit Tool Version 2 (HEPA PAT v2) of the World Health Organization, a tool was designed to support local governments in assessing HEPA policies. This study aims to describe the adaptation and testing of the HEPA policy analysis tool (CAPLA-Santé) at the local level in France. The work was conducted in three stages: (1) an intersectoral group of experts was constituted, and the group adapted each item of the HEPA PAT v2 tool to the local level; (2) a testing phase with seven local governments helped to collect data and feedback on the tool; and (3) a final workshop was organized to adjust and finalize the tool. The final version of CAPLA-Santé contains 21 items divided into six major sections: overview of HEPA stakeholders in the local government area, policy documents, policy contents, funding and political engagement, studies and measures relating to physical activity in the local government area, and progress achieved and future challenges. CAPLA-Santé allows the collection and in-depth analysis of local level policies to assess the progress in promoting HEPA and intersectoral collaboration as well as identifying successful policy levers and remaining challenges.

Health Promotion Practice

Month XXXX Vol. XX, No. (X) 1-9

DOI: $10.1177 / 1524839920916462$

Article reuse guidelines: sagepub.com/journals-permissions
Keywords: health promotion; physical activity; local government; policy; assessment

$\mathrm{H}$ ealth-enhancing physical activity (HEPA) policies have been developed over the past few years by governments at the national and subnational levels (Breda et al., 2018; Daugbjerg et al., 2009; Varela et al., 2017; Wilkinson, 2006). The increased recognition of the importance of physical activity as a policy area was supported by the development of policy frameworks by the World Health Organization (WHO), which encourages the development and the implementation of national and subnational policies promoting HEPA across multiple sectors (WHO, 2016, 2018).

${ }^{1}$ Université Côte d'AzurNice, France

${ }^{2}$ Université de Lorraine, Nancy, France

${ }^{3}$ Société Française de Santé Publique, Laxou, France

${ }^{4}$ Université de Bordeaux, Bordeaux, France

Authors' Note: We would like to thank the members of the CAPLASanté expert group, department heads, and elected officials who participated to this study. A sincere thank you to Stacey Johnson for her diligent proofreading of this article. This work was supported by a PhD grant from the Région Sud; the association Azur Sport Santé and the Direction Générale de la Santé, Ministry of Health; and Santé Publique France. Address correspondence to Anne Vuillemin, Faculté des Sciences du Sport, Laboratoire Motricité Humaine Expertise Sport Santé, Université Côte d'Azur, 261 Boulevard du Mercantour, Nice, 06205, France; e-mail: anne. vuillemin@univ-cotedazur.fr. 
According to the literature on "health in all policies," the integration of health issues, such as physical activity, into policy decision making across intersectoral collaborations is a key factor of success in promoting health (De Leeuw \& Clavier, 2011; Ollila, 2011). To help foster intersectoral collaboration and to provide a comprehensive overview of national HEPA policies, the WHO developed the HEPA Policy Audit Tool (PAT) with an updated version published in 2015, Version 2 (Bull et al., 2014; WHO, 2015). The HEPA Policy Audit Tool Version 2 (HEPA PAT v2) is structured in a "questionand-answer" format (28 items in 11 sections) based on the literature and on a pilot study conducted in seven countries. The instrument may be addressed to key informants from a broad range of sectors involved in the development of HEPA policies. This standardized tool allows the collection and compilation of data related to national policies (e.g., context, process, content, and implementation) in order to assess the progress in promoting HEPA and intersectoral collaboration, and to identify successful policies levers (Bull et al., 2014). The HEPA PAT has been pilot tested in seven European countries (Bull et al., 2015), including France (PrévotLedrich et al., 2016; Van Hoye et al., 2019), and used in countries of the Eastern Mediterranean region (WHO, 2014). All of these studies pointed out the importance of the local level for HEPA promotion because this is the level where people live, work, and play. Thus, local governments have a crucial role in HEPA promotion (Wilkinson, 2006). Local government may be defined as "local authorities at city/municipal, or county, or regional/state level” (Spitters et al., 2017). These locallevel authorities have the capacity to define and implement policies that may support a community's ability to be active, by integrating a multisectoral approach (Wilkinson, 2006). Moreover, previous work suggested that collaboration at both the national and local levels is needed in order to develop the practice of physical activity (Cavill et al., 2006; Vuori et al., 2004).

In France, a decentralization process has transferred some legal and "discretionary" jurisdictions (optional according to the law) from the national government to local governments (Halpern et al., 2018). Depending on the type and scale of local governments (city, metropolitan area, county, or region), the power of local authorities to implement HEPA policies may be different. However, most of them have the legal power to act on many determining factors affecting health across sectors such as urban development, environmental, social, sports, and health services. Thus, local government has a major role to play in the promotion of HEPA by implementing intersectoral policies (Bull et al., 2014; Bull et al., 2015; Wilkinson, 2006).
While the literature on this topic at the national level is increasing (Klepac Pogrmilovic et al., 2018), little is known about local evidence of HEPA policies to support local governments (Bull, 2018). Moreover, a recently developed framework for physical activity policy analysis highlights the need for analysis of local-level policies (Klepac Pogrmilovic et al., 2019). Although the HEPA PAT contains some questions concerning the local level (Bull et al., 2014; WHO, 2015), there are no standardized instruments to capture the relevant local HEPA policy information. Therefore, based on the HEPA PAT v2 a local HEPA PAT was developed in French (CAPLA-Santé: analysis tool for local HEPA). This article aims to report on the development and pilot testing of CAPLA-Santé designed to carry out the collection of comprehensive information on local HEPA policies.

\section{METHOD}

CAPLA-Santé was developed between September 2017 and July 2018. The work was conducted in three stages: (1) adaptation of the HEPA PAT v2 to the local level, (2) pilot testing, and (3) formalization of the final version of the tool.

\section{Adaptation of the HEPA PAT v2 to the Local Level}

A multidisciplinary panel of intersectoral experts was constituted $(n=17)$ representing different organizations that included researchers, professionals, national, and local policy makers from the health, sport, and transport sectors (Table 1).

The project was initiated by exploring the scientific literature on local governmental HEPA policies to guide the development of CAPLA-Santé. Two independent researchers searched in seven databases to extract peer-reviewed research articles published in English between January 2006 and December 2016. A total of 21 articles were extracted. From these results, some specificities at the local level were identified, such as territorial and contextual variables that could influence HEPA policies: territory size, urban or rural context, human resources and funding, coordination of local governments at different sublevels, involvement and relationships between stakeholders, community support, characteristics of the community, and characteristics of the built and natural environment. These specificities were taken into consideration for the adaptation of the HEPA PAT v2 (Bull et al., 2014; WHO, 2015).

Six workshops were organized with the panel of experts to adapt the HEPA PAT v2 (Bull et al., 2014; 
TABLE 1

The Multidisciplinary and an Intersectoral Experts' Panel

\begin{tabular}{lll}
\hline Organization & No. of experts & Sector \\
\hline Ministry for Solidarity and Health & 1 & Health \\
National Public Health Agency & 1 & Health \\
French Society of Public Health & 2 & Health \\
French National Olympic and Sports Committee & 2 & Sports \\
Regional Directorate for Youth, Sports and Social Cohesion, & 1 & Sports \\
$\quad$ Ministry of Sports & 1 & Transport \\
Inter-ministerial Coordination for the Development of Walking & & Sports and health \\
$\quad$ and Bicycle Use, Ministry of Ecological and Solidarity Transition & 2 & Higher education and research \\
French Society of Exercise and Sports Medicine & 2 & Higher education and research \\
Université Côte d'Azur (1 academic and 1 PhD student) & 1 & Higher education and research \\
University of Lorraine (1 academic) & 1 & Higher education and research \\
University of Bordeaux (1 academic) & 1 & Social \\
University of Liège & 1 & Multisectoral \\
General Commission for Territorial Equality & 1 & \\
World Health Organization French Healthy Cities Network & & \\
\hline
\end{tabular}

WHO, 2015) to the local level (Table 2). Items and sections were added or deleted, duplicate ideas were condensed, and wording of the statement elements was enhanced to improve clarity and representativeness. The aim was to optimize the clarity of the use of CAPLASanté by different types of stakeholders (e.g., policy makers, policy implementers, researchers, etc.) from various sectors.

\section{Pilot Testing}

The pilot testing was carried out from February 2018 to June 2018. The first version of CAPLA-Santé was tested on local governments at the subnational level, in two territories located in the South and the East of France. In each pilot territory, a coordinator from the panel of experts contacted local governments at different administrative levelsto voluntarily participate in the

TABLE 2

Details of the Workshop's Tasks

\begin{tabular}{|c|c|}
\hline Workshop & Workshop tasks \\
\hline Workshop 1 (October 2017) & $\begin{array}{l}\text { - Presentation of the results of the scoping review on local governmental policies } \\
\text { promoting HEPA } \\
\text { - Sharing definitions of the key terms and reaching a consensus: "policy," "local } \\
\text { government," and "physical activity" } \\
\text { - First brainstorming session: adaptation of each section and items of the HEPA } \\
\text { PAT v2 to the local level }\end{array}$ \\
\hline Workshop 2 (November 2017) & $\begin{array}{l}\text { - Second brainstorming session: reaching a consensus from panel experts to adapt } \\
\text { each section and item of the HEPA PAT v2 to the local level }\end{array}$ \\
\hline $\begin{array}{l}\text { Workshop } 3 \text { and } 4 \text { (December } \\
\text { 2017-January 2018) }\end{array}$ & - Work on the protocol for the pilot testing \\
\hline Workshop 5 (February 2018) & - Protocol validation for the pilot testing \\
\hline Workshop 6 (July 2018) & $\begin{array}{l}\text { - Finalization and formalization of the first version "CAPLA-Santé" following the } \\
\text { pilot testing }\end{array}$ \\
\hline
\end{tabular}

Note. HEPA = health-enhancing physical activity; HEPA PAT v2 = HEPA Policy Audit Tool Version 2. 
pilot testing. The objective was to recruit a minimum of one local government at different levels (city, metropolitan area, county, region). Local governments were initially contacted by email. In order to test and collect comprehensive information on local policy, the coordinator had, for each local fovernment, to (1) collect and review written HEPA policy documents from the local government through websites and conduct interviews with key informants from several sectors (health, sport, transport, urban, environment). These policy documents could be strategies, action plans, guidelines, deliberations, local authority articles of association, memos, meeting reports, electoral programs, or website information, and (2) address all items of the tool to key informants through structured interviews. During the interviews a glossary of key terms was provided to key informants to explain the concept, such as HEPA, policy, or local level.

Through interviews, key informants provided qualitative feedback on the clarity, relevance, and acceptability of all items. Each structured interview was digitally recorded and transcribed verbatim. Their feedback was used to formalize the final version of CAPLA-Santé during the final workshop (Table 2).

Moreover, when the local government was volunteered, a meeting involving the interviewed key informants was proposed to validate, in a collective way, the information collected using CAPLA-Santé. This step aimed to add elements helping to improve the use of CAPLA-Santé and to understand in which way it could be used by policy makers.

\section{Formalization of the Final Version of CAPLA-Santé}

A final workshop was organized with the panel of experts in order to reach a consensus on the final version of the tool. The coordinators presented the data collection results including qualitative feedback from key informants on the clarity and the relevance of items. Based on these results, the panel of experts reviewed certain items of the tool. Consensus was then reached on the final version of CAPLA-Santé.

\section{RESULTS}

\section{Adaptation of the HEPA-PAT to the Local Level}

During the workshop sessions, some key notions were debated, such as "policy," "action," "intervention," and "the scale of the local level." As policy is a broad field, the group of experts decided to use the same definition of policy that was used in the HEPA PAT v2 for the national level: "Written document that contains priorities, defines goals and objectives, and usually [comes from a specific sector of] public administration" (WHO, 2015, p. 7; Bull et al., 2014).

The group of experts decided to consider the local level from local government scales: city, county, and regional levels as defined by Spitters et al. (2017). Thus, each notion defined and shared by the group of experts allowed them to reach a consensus on the item's adaptation to the local level.

Of the 28 items of the HEPA PAT v2 (Bull et al., 2014; WHO, 2015), seven items were not considered to be relevant for the local level and were excluded (Items 1, $4,11,15,18,19,26)$. All of the 21 remaining items were translated into French and 17 items were adapted to the local level. Consequently, of the 11 sections of the HEPA PAT v2 (Bull et al., 2014; WHO, 2015), two were excluded (Sections 1 and 9), Ssections 4 and 5 were merged, and Sections 3 to 7 were merged to provide six sections in total.

By the end of the last workshop, a first version of CAPLA-Santé was drafted. The tool contained 21 items divided into six major sections: (1) overview of stakeholders involved in the promotion of HEPA in the territory (5 items), (2) policy documents (3 items), (3) policy contents (6 items), (4) funding and political engagement (1 item), (5) studies and measures related to physical activity in the territory (3 items), and (6) progress achieved and challenges to be addressed (3 items).

\section{Pilot Testing}

Seven local governments participated in the pilot testing phase: city $(n=4)$, metropolitan area $(n=1)$, county $(n=1)$, and region $(n=1$; Table 3$)$. Key informants interviewed $(n=20)$ were from the sports $(n=$ $10)$, health $(n=6)$, transport $(n=2)$, urban development $(n=1)$, and environmental $(n=1)$ sectors. Both coordinators that led the data collection using semistructured interviews reported some difficulties in identifying key informants involved in the promotion of HEPA in local governments. According to the local governments, the sectors and people involved in HEPA promotion were different, making it difficult to identify a key informant. For example, in some local governments, the health sector has a specific dedicated service, whereas in other local governments, this service was lacking or merged with another, as in France, each local government can organize their departments as they wish. Most key informants were department heads $(n=18)$, and a few were elected officials $(n=2)$.

The semistructured interviews with the local government "F" (county level) and "G" (regional level) did not allow the completion of most of the items of the first version of CAPLA-Santé. Participants could only complete 
TABLE 3

Type of Local Governments and Key Informants

\begin{tabular}{llcl}
\hline Local governments & Type of local authorities & No. of key informants interviewed & Represented sectors \\
\hline A & City & 4 & Sports, health, urban development \\
B & City & 3 & Sports, health \\
C & City & 2 & Sports, environment \\
D & City & 3 & Sports, health, transportation \\
E & Metropolis & 3 & Sports, health \\
F & County & 2 & Sports, health \\
G & Region & 3 & Sports, health, transportation \\
\hline
\end{tabular}

items from Section 1 on the overview of stakeholders involved in the promotion of HEPA in the territory. Nevertheless, participants from these governments were able to identify a few stakeholders. Other items could not be completed because these local governments did not have any HEPA policies. For other local governments (A, B, C, D, and E), the cross-data collection through semistructured interviews made it possible to complete all items of the first CAPLA-Santé. Sometimes, the key informant alone was not able to provide information for certain items, but these items were completed afterward by key informants from other sectors of the same local government as already found at the national level (Bull et al., 2014; Bull et al., 2015).

Key informants gave qualitative feedback on the clarity and the relevance of the items on the first version of CAPLA-Santé. Although a list of key terms was provided (HEPA, policy, local level), sometimes items seemed confusing to some key informants due to a different representation of certain key notions such as policy/action, coordination/collaboration, and sedentary/inactivity. Following this, a broader list of terms was created and improved to help stakeholders clearly understand the items.

A total of 28 written HEPA policy documents were collected and reviewed (Figure 1), coming from different sectors: transport $(n=8)$, sports $(n=7)$, environmental $(n=4)$, health $(n=3)$, education $(n=3)$, and social $(n=3)$. Sometimes, written HEPA policy documents were not identified by the coordinators during the document review on local government websites but were identified during the semistructured interviews with key informants. Most of them were not published on local government websites but were internal documents. In contrast, sometimes written HEPA policy documents were identified by the coordinators during the document review, but key informants were not aware of them. Sometimes, key informants confused written HEPA policies with actions. The classification of a document as a written HEPA policy was not always easy. Collected HEPA policy documents were usually not detailed, or were not downloadable, they were succinctly described on the website without further information. Some information had to be supplemented or explained by key informants in order to have a better understanding of the context of the policy.

Local Governments A and D were volunteered to organize a collective meeting to validate the information collected using CAPLA-Santé. Key informants from the sports (elected official and department head), health (department head), and urban development sectors (department head; $n=4$ ) participated in the focus group of local Government A. Key informants from the health (department head), urban development (department head), and environmental sectors (elected official; $n=4$ ) participated in the collective meeting of local Government B. CAPLA-Santé was perceived as being "useful for promoting discussion and collaboration among the various departments of our city" (department head). Some elected officials and department heads would use the tool as a catalyst and an advocacy tool to promote HEPA in their territories: "The promotion of HEPA is a new strategy in the development of local policies" (elected official). Moreover, it could "stimulate a global approach to HEPA through an intersectoral dynamic" (department head). The overview of local HEPA policies that can produce CAPLA-Santé "could help to formalize a global HEPA policy" and "highlight intersectoral action" (elected official).

The complete process of using CAPLA-Santé took 6 months and included (1) contacts with local governments, (2) document reviews, (3) semistructured interviews, (4) reporting and summarizing data, and (5) collective meeting to validate the information collected using CAPLA-Santé. 


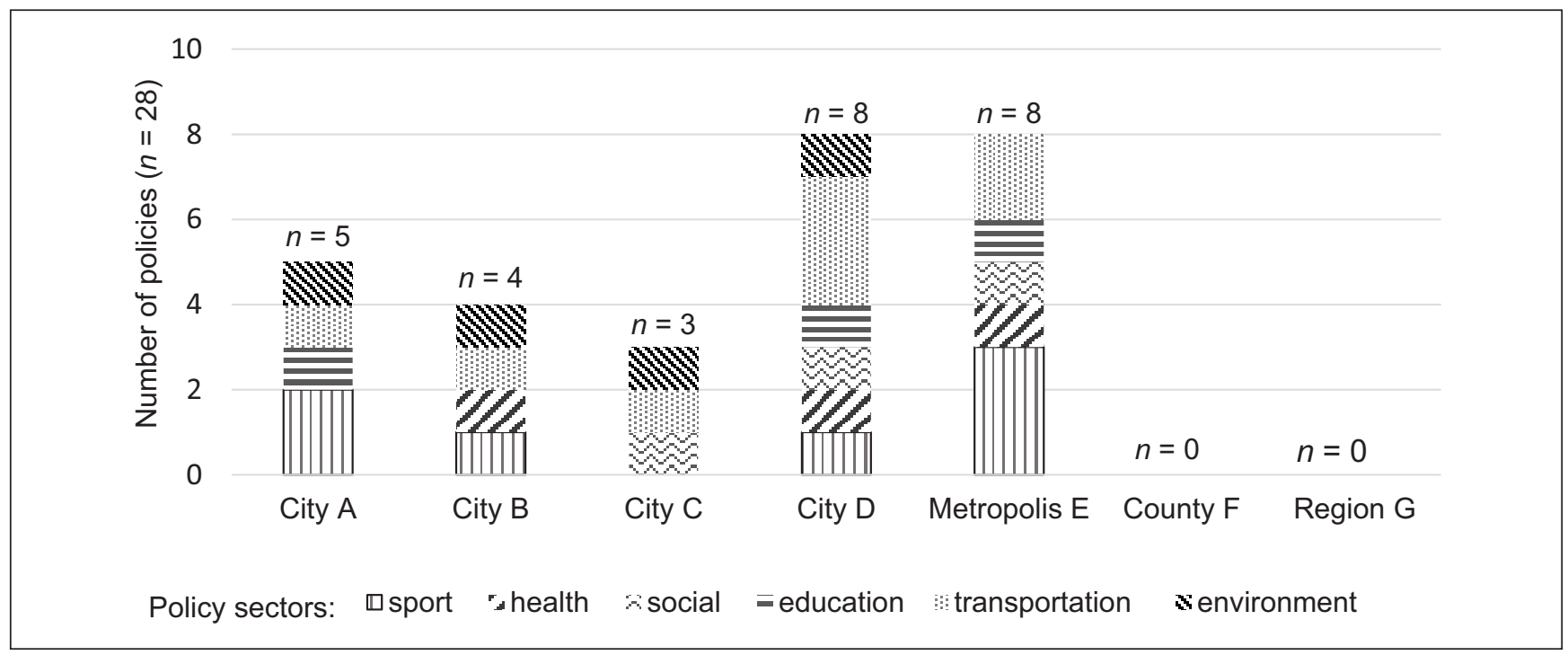

FIGURE 1 Written HEPA Documents Collected From Local Governments

\section{Formalization of the Final Version of CAPLA-Santé}

Based on pilot testing, the final version of CAPLASanté contained 21 items divided into six major sections. The type and number of items and major sections did not change from the first version. According to user experience during pilot testing, all items seemed to be relevant. However, based on the feedback of key informants, some items were discussed $(n=11)$, and rephrased $(n=10)$ to enhance clarity.

Following the finalization of the last version of CAPLA-Santé and based on pilot testing, a glossary of terms, an interview grid, an accompanying guide, and an inventory of potential policy documents and funding and data sources were developed to facilitate the use and dissemination of the tool. CAPLA-Santé is available in English in the Supplemental Material.

\section{DISCUSSION}

From the adaption of the HEPA PAT v2 (Bull et al., 2014; WHO, 2015) by a multidisciplinary and intersectoral group of experts, a local HEPA policy analysis tool was developed: CAPLA-Santé. This tool provides an overview of HEPA policies at the local level.

The main challenge in adapting the HEPA PAT v2 (Bull et al., 2014; WHO, 2015) was to take into account specificities of the local level compared with the national level. Many contextual variables could affect local HEPA policy (Reis et al., 2016). In addition, structural variables could also affect local HEPA policies, like the local government system's organization. The French local governmental system is organized at different levels (e.g., municipality, metropolis, county, region) and with different types of administration, with different responsibilities and authorities (Halpern et al., 2018). Moreover, these local governments can decide for themselves how to organize their departments. For example, in the pilot test some municipalities had a health sector department, whereas others did not. Therefore, items of CAPLASanté were adapted to take into account the particularities of the local governmental system as it is organized in France.

The type, scale, and jurisdiction of local governments may be different in other countries. Thus, the responsibilities and characteristics of local governments may influence the way in which HEPA policies are developed and implemented. The political structure and system organization influences the way in wich physical activity policies are delivered at he local level, as shown by Bull et al. (2014) in the development of the HEPA PAT v2.

Another important aspect of the adaptation of HEPA PAT v2 (Bull et al., 2014; WHO, 2015) to CAPLA-Santé was the translation of key terms into French. The terms used in CAPLA-Santé were different from the terminology used in the original HEPA PAT v2 (Bull et al., 2014; WHO, 2015). Modifications of terms were requested by the workshop participants to make the tool understandable for policy makers at the local level. The pilot testing showed that if the list of terms provided was not completed and clear, policy makers were often confused.

Results showed several difficulties for potential users: Key terms were not always understandable, identifying key informants was challenging, and HEPA 
policy documents were complex. Therefore, based on the experience of the pilot testing, several documents were created, such as a glossary of terms, an interview grid, an accompanying guide, and an inventory of potential policy documents and funding and data sources. Most of these documents, which aim to help users, did not exist in the HEPA PAT v2 at the national level (Bull et al., 2014; WHO, 2015).

While the HEPA PAT v2 contains some questions concerning the local level (Bull et al., 2014; WHO, 2015), CAPLA-Santé includes some questions related to the national level. The use of the HEPA-PAT allowed researchers to discover that local level government is important when implementing national policy (Bull et al., 2015; Prévot-Ledrich et al., 2016; Van Hoye et al., 2019; WHO, 2014). Although some local governments can develop HEPA policies without the support of national policies, the use of CAPLA-Santé could assess how national policy influences the development of HEPA policies at local levels.

Another added element compared to the HEPA PAT v2 (Bull et al., 2014; WHO, 2015) was the data collection from both department heads (who usually implement policies) and, whenever possible, from elected officials. Collecting both types of perceptions of the framing and implementation of HEPA policies provides a better overview of policy progress (Muellmann et al., 2017). Adding the point of view of elected officials allows an understanding of how and why local governments decide to develop a HEPA policy. In that way, barriers and levers of political decisions concerning HEPA promotion can be identified in more depth.

Regarding the importance of concepts such as "health in all polices" with intersectoral collaboration in the public health field (De Leeuw \& Clavier, 2011; Ollila, 2011), it was important to systemically collect data from different sectors thanks to the triangulation between interviews and reviewed documents, as is proposed in CAPLA-Santé. All the more so, as the local level seems to be a good arena for implementing intersectoral collaboration (Rantala et al., 2014). During this pilot testing phase, key informants were sometimes unaware of HEPA policies implemented by other sectors of their local government. They usually did not adopt a global and intersectoral HEPA policy, especially when these areas were outside of health and sports. These types of results were also observed at the national level when the HEPA PAT V2 was used in France by Prévot-Ledrich et al. (2016): In the absence of a global policy promoting physical activity, few sectors were involved and lacked coordination. Thus, CAPLA-Santé could highlight and enhance the mechanisms of intersectoral collaboration and coordination existing at the local level.
Using a collective consensus process with semistructured interviews and meetings, CAPLA-Santé was collaboratively produced by policy makers, professionals, and researchers from different sectors or disciplines. From this complex interplay, this tool analyzing local HEPA polices could be used as an interface between research, policy, and practice. The literature highlighted the need to bridge the gap between evidence and action (Brownson \& Jones, 2009). While developing CAPLASanté, this method, which involved various stakeholders working on the promotion of HEPA, allowed different types of knowledge to be integrated. In this way, the tool was able to better embrace the complexity of local HEPA policies and capture relevant policy information.

\section{Limitations}

This study had certain limitations. Although CAPLASanté could be adapted to other country contexts, some modified items of the HEPA PAT v2 (Bull et al., 2014; WHO, 2015) to the local level are specific to the French context such as the policy system organization at the subgovernmental level. The HEPA PAT was improved with a second version based on user experiences (Bull et al., 2014; WHO, 2015), CAPLA-Santé could also be improved through an iterative process. Furthermore, CAPLA-Santé might not consider all aspects of local HEPA policies, the political decision-making process, or the policy change over time. During the development of the tool, the intersectoral group of experts may have neglected to add certain items. Local governments included in the pilot test may not be completely representative because they were not randomly selected but resulted from previous contacts with the coordinator of the expert panel. During the development of the tool, the time allowed for the testing phase was limited, and it proved difficult to contact local volunteer governments.

\section{Implications for Practice, Policy, and Research}

Based on the HEPA PAT v2 of the WHO (2015; Bull et al., 2014), CAPLA-Santé was designed to provide a process to overview HEPA policies at the local French level. Pilot testing suggests that this local HEPA PAT tool allows the collection and in-depth analysis of policy and context in order to assess the progress of the promotion of HEPA, intersectoral collaboration, and the identification of successful policy levers. Using mixed methods with key informants across multiple sectors, CAPLA-Santé could prove to be useful for researchers, policy makers (e.g., elected officials), policy implementers (department heads), or any other stakeholders involved in the promotion of HEPA. It could be used as a decision making and advocacy tool 
for local stakeholders or as a process framework for collecting and analyzing policy data for researchers. Broader research with this standardized instrument is now needed in order to better understand the development and implementation of HEPA policies, while taking the local context into account. Results of this research could help strengthen the capacity of local governments in building HEPA policies.

\section{ORCID iDs}

Antoine Noël Racine (iD https://orcid.org/0000-0001-9513-9248 Anne Vuillemin (iD) https://orcid.org/0000-0002-5778-0285

\section{SUPPLEMENTAL MATERIAL}

Supplemental Material for this article is available at https://journals.sagepub.com/home/hpp.

\section{REFERENCES}

Breda, J., Jakovljevic, J., Rathmes, G., Mendes, R., Fontaine, O., Hollmann, S., Rütten, A., Gelius, P., Kahlmeier, S., \& Galea, G. (2018). Promoting health-enhancing physical activity in Europe: Current state of surveillance, policy development and implementation. Health Policy, 122(5), 519-527. https://doi.org/10.1016/j. healthpol.2018.01.015

Brownson, R. C., \& Jones, E. (2009). Bridging the gap: Translating research into policy and practice. Preventive Medicine, 49(4), 313315. https://doi.org/10.1016/J.YPMED.2009.06.008

Bull, F. (2018). Translating science to inform global policy on physical activity. Journal of Sport and Health Science, 7(1), 3-4. https:// doi.org/10.1016/j.jshs.2017.10.005

Bull, F. C., Milton, K., \& Kahlmeier, S. (2014). National policy on physical activity: The development of a policy audit tool. Journal of Physical Activity \& Health, 11(2), 233-240. https://doi.org/10. 1123/jpah.2012-0083

Bull, F., Milton, K., Kahlmeier, S., Arlotti, A., Juričan, A. B., Belander, O., Martin, B., Martin-Diener, E., Marques, A., Mota, J., Vasankari, T., \& Vlasveld, A. (2015). Turning the tide: National policy approaches to increasing physical activity in seven European countries. British Journal of Sports Medicine, 49(11), 749-756. https://doi.org/10.1136/bjsports-2013-093200

Cavill, N., Foster, C., Oja, P., \& Martin, B. W. (2006). An evidencebased approach to physical activity promotion and policy development in Europe: contrasting case studies. Promotion $\&$ Education, 13(2), 104-111. https://doi.org/10.1177/10253823060130020104

Daugbjerg, S. B., Kahlmeier, S., Racioppi, F., Martin-Diener, E., Martin, B., Oja, P., \& Bull, F. (2009). Promotion of physical activity in the European region: Content analysis of 27 national policy documents. Journal of Physical Activity \& Health, 6(6), 805-817. https://doi.org/10.1123/JPAH.6.6.805

De Leeuw, E., \& Clavier, C. (2011). Healthy public in all policies. Health Promotion International, 26(2), 237-244. https://doi. org/10.1093/heapro/dar071

Halpern, C., Hassenteufel, P., \& Zittoun, P. (2018). Policy analysis in France. Bristol University Press. https://doi.org/10.2307/j. ctt1zqrn8r
Klepac Pogrmilovic, B., O’Sullivan, G., Milton, K., Biddle, S. J. H., Bauman, A., Bellew, W., Cavill, N., Kahlmeier, S., Kelly, M. P., Mutrie, N., Pratt, M., Rutter, H., Varela, A. R., Woods, C., \& Pedisic, Z. (2019). The development of the Comprehensive Analysis of Policy on Physical Activity (CAPPA) framework. International Journal of Behavioral Nutrition and Physical Activity, 16(1), Article 60. https://doi.org/10.1186/s12966-019-0822-5

Klepac Pogrmilovic, B., O’Sullivan, G., Milton, K., Biddle, S. J. H., Bauman, A., Bull, F., Kahlmeier, S., Pratt, M., \& Pedisic, Z. (2018). A global systematic scoping review of studies analysing indicators, development, and content of national-level physical activity and sedentary behaviour policies. International Journal of Behavioral Nutrition and Physical Activity, 15(1), Article 123. https://doi. org/10.1186/s12966-018-0742-9

Muellmann, S., Steenbock, B., De Cocker, K., De Craemer, M., Hayes, C., O’Shea, M. P., Horodyska, K., Bell, J., Luszczynska, A., Roos, G., Langøien, L. J., Rugseth, G., Terragni, L., De Bourdeaudhuij, I., Brug, J., \& ischke, C. R. (2017). Views of policy makers and health promotion professionals on factors facilitating implementation and maintenance of interventions and policies promoting physical activity and healthy eating: Results of the DEDIPAC project. BMC Public Health, 17(1), 932. https://doi. org/10.1186/s12889-017-4929-9

Ollila, E. (2011). Health in all policies: From rhetoric to action. Scandinavian Journal of Public Health, 39(6), 11-18. https://doi. org/10.1177/1403494810379895

Prévot-Ledrich, J., Van Hoye, A., Lombrail, P., Lecomte, F., \& Vuillemin, A. (2016). Overview of French public policies promoting health-enhancing physical activity. Sante Publique (VandoeuvreLes-Nancy, France), 28(Suppl. 1), S25-S31. https://doi.org/10.3917 /spub.160.0025

Rantala, R., Bortz, M., \& Armada, F. (2014). Intersectoral action: Local governments promoting health. Health Promotion International, 29(1), i92-i102. https://doi.org/10.1093/heapro /dau047

Reis, R. S., Salvo, D., Ogilvie, D., Lambert, E. V, Goenka, S., Brownson, R. C., \& Lancet Physical Activity Series 2 Executive Committee. (2016). Scaling up physical activity interventions worldwide: Stepping up to larger and smarter approaches to get people moving. Lancet, 388(10051), 1337-1348. https://doi.org/10. 1016/S0140-6736(16)30728-0

Spitters, H., Lau, C., Sandu, P., Quanjel, M., Dulf, D., Glümer, C., van Oers, H., \& Van de Goor, I. (2017). Unravelling networks in local public health policymaking in three European countries: A systems analysis. Health Research Policy and Systems, 15(1), Article 5. https://doi.org/10.1186/s12961-016-0168-2

Van Hoye, A., Vandoorne, C., Absil, G., Lecomte, F., Fallon, C., Lombrail, P., \& Vuillemin, A. (2019). Health enhancing physical activity in all policies? Comparison of national public actors between France and Belgium. Health Policy, 123(3), 327-332. https://doi.org/10.1016/J.HEALTHPOL.2019.01.008

Varela, A. R., Pratt, M., Powell, K., Lee, I. M., Bauman, A., Heath, G., Martins, R. C., Kohl, H., \& Hallal, P. C. (2017). Worldwide surveillance, policy, and research on physical activity and health: The global observatory for physical activity. Journal of Physical Activity \& Health, 14(9), 701-709. https://doi.org/10.1123/jpah.2016-0626 Vuori, I., Lankenau, B., \& Pratt, M. (2004). Physical activity policy and program development: The experience in Finland. Public 
Health Reports, 119(3), 331-345. https://doi.org/10.1016/j.phr. 2004.04.012

Wilkinson, R. (2006). The solid facts: Promoting physical activity and active living in urban environments: The role of local governments (WHO Regional Publications, European Series No 89). World Health Organization.

World Health Organization. (2014). Tenth annual meeting of HEPA EuropeEuropean network for the promotion of healthenhancing physical activity. Report of a WHO meeting, 28-29 August 2014, Zurich, Switzerland. http://www.euro.who.int/ __data/assets/pdf_file/0004/288580/Tenth-annual-meeting-ofHEPA-Europe-Zurich-rev1.pdf?ua=1
World Health Organization. (2015). Health-enhancing physical activity (HEPA) policy audit tool (PAT): Version 2 (2015). http:// www.euro.who.int/en/health-topics/disease-prevention/physical -activity/publications/2015/health-enhancing-physical-activity -hepa-policy-audit-tool-pat-version-2-2015

World Health Organization. (2016). Physical activity strategy for the WHO European Region 2016-2025. World Health Organisation Regional Office for Europe.

World Health Organization. (2018). Global action plan on physical activity 2018-2030: More active people for a healthier world. Global action plan on physical activity 2018-2030. https://apps.who.int /iris/bitstream/handle/10665/272722/9789241514187-eng.pdf 